\title{
Do male engagement and couples' communication influence maternal health care-seeking? Findings from a household survey in Mozambique
}

Gilda G. Sitefane ${ }^{1}$, Joya Banerjee $2^{2^{*}}$ (D), Diwakar Mohan ${ }^{3}$, Connie S. Lee ${ }^{2}$ Jim Ricca², Myra L. Betron² and Rosa Marlene Manjate Cuco ${ }^{4}$

\begin{abstract}
Background: This study explored effects of couples' communication and male participation in birth preparedness and complication readiness (BPCR) on delivery in a health facility ("institutional delivery"). A cross-sectional, baseline household survey was conducted in November 2016 prior to an integrated maternal and child health project in Nampula and Sofala Provinces in Mozambique.

Methods: The study used the Knowledge, Practices and Coverage survey tool, a condensed version of the Demographic and Health Survey and other tools. The sample included 1422 women. Multivariable logit regression models tested the association of institutional delivery with couples' communication and four elements of BPCR both with and without male partners: 1) saving money, 2) arranging transport, 3) choosing a birth companion, and 4) choosing a delivery site; controlling for partners' attendance in antenatal care and social and demographic determinants (education, wealth, urban/rural location, and province).

Results: The odds that women would deliver in a health facility were $46 \%$ greater (adjusted odds ratio $(a O R)=1.46$, $95 \%$ confidence interval $(C \mathrm{I})=1.02-2.10, p=0.04$ ) amongst women who discussed family planning with their partners than those who did not. Approximately half of this effect was mediated through BPCR. When a woman arranged transport on her own, there was no significant increase in institutional delivery, but with partner involvement, there was a larger, significant association $(a O R=4.31,2.64-7.02)$. Similarly, when a woman chose a delivery site on her own, there was no significant association with institutional delivery (aOR 1.52,0.81-2.83), but with her partner, there was a larger and significant association (aOR 1.98, 1.16-3.36). Neither saving money nor choosing a birth companion showed a significant association with institutional delivery - with or without partner involvement. The odds of delivering in a facility were $28 \%$ less amongst poor women whose partners did not participate in BPCR than wealthy women, but when partners helped choose a place of delivery and arrange transport, this gap was nearly eliminated.

(Continued on next page)
\end{abstract}

* Correspondence: Joya.banerjee@gmail.com

${ }^{2}$ Maternal and Child Survival Program/ Jhpiego, 1776 Massachusetts Ave, NW, Suite 300, Washington, DC 20036, USA

Full list of author information is available at the end of the article

C C The Author(s). 2020 Open Access This article is licensed under a Creative Commons Attribution 4.0 International License, which permits use, sharing, adaptation, distribution and reproduction in any medium or format, as long as you give appropriate credit to the original author(s) and the source, provide a link to the Creative Commons licence, and indicate if changes were made. The images or other third party material in this article are included in the article's Creative Commons licence, unless indicated otherwise in a credit line to the material. If material is not included in the article's Creative Commons licence and your intended use is not permitted by statutory regulation or exceeds the permitted use, you will need to obtain permission directly from the copyright holder. To view a copy of this licence, visit http://creativecommons.org/licenses/by/4.0/ The Creative Commons Public Domain Dedication waiver (http://creativecommons.org/publicdomain/zero/1.0/) applies to the data made available in this article, unless otherwise stated in a credit line to the data. 
(Continued from previous page)

Conclusions: Our findings add to growing global evidence that men play an important role in improving maternal and newborn health, particularly through BPCR, and that couples' communication is a key approach for promoting high-impact health behaviors.

Keywords: Gender, Male engagement, Couples' communication, Birth preparedness, Complication readiness, Institutional delivery, Mozambique, Maternal health, Family planning, Antenatal care

\section{Background}

Mozambique's maternal mortality ratio stands at 489 per 100,000 live births as of 2015 , one of the highest in the world [1]. The country has made significant progress in encouraging women to deliver in health facilities, with a nationwide institutional delivery rate of $70.3 \%$ [2]. However, progress has been uneven, with a rate of $88 \%$ in Sofala Province but only $68 \%$ in Nampula [2]. A scoping study in three provinces in Mozambique found that the most significant barriers to giving birth in a health facility and delays in seeking care were mostly due to gender barriers, particularly the influence of family and partners [3].

In Mozambique, women are seldom the main decision makers in relationships [4], they have lower levels of literacy than men, [5] and gender and social norms often dictate that they obey their male partners [6]. A study by Audet et al. on the barriers to male involvement in antenatal care (ANC) in Zambézia Province of Mozambique, found that women had the lowest proportion of ANC uptake in the country, despite the availability of free services. The authors identified gender inequality and a lack of male support as one of the main causes of low ANC participation, and noted that "[a]ll groups participating in this study discussed the need for male partners to provide logistic, financial, and psychological support to increase uptake of ANC services." [7] Women were considered responsible for the health of the baby during pregnancy, and men did not see the baby as their responsibility until after birth [7]. In some cases, men did want to be involved, but there was a lack of support for male involvement from members of their community, particularly from other men. Men who provided emotional or physical support to a pregnant partner or accompanied her to an ANC visit were often mocked by friends [7].

A systematic review of male involvement in prevention of mother-to-child transmission interventions in subSaharan Africa [8] found that men who visited health facilities for HIV testing during ANC visits often felt that services were unfriendly to men [9-12] felt ignored by providers [10], or felt the facilities were dominated by women as both patients and providers [9]. Audet et al. also found that stigma surrounding HIV was a significant barrier to uptake of ANC [7]. Because HIV testing and counseling is a routine feature of ANC, a woman is often first diagnosed during an ANC visit, leading to the belief in the community that a woman's uptake of ANC services, particularly if supported by a male partner, may mean that she or he is HIV positive [7].

Since the mid-1990s, there has been a growing recognition of the importance of male engagement in reproductive, maternal, neonatal, child, and adolescent health (RMNCAH) interventions [13-15]. The World Health Organization (WHO) now includes it as a critical component of ANC to improve birth outcomes [16]. A systematic review by Tokhi et al. of the effectiveness of interventions to involve male partners in improving maternal and newborn health found that men's involvement improved ANC attendance, institutional delivery, postpartum care, and maternal nutrition [15]. Evidence was less clear on the impact of male engagement interventions on their participation in birth preparedness and complication readiness (BPCR), with some studies showing an effect, and others not [15].

BPCR is a counseling approach that includes elements of antenatal, intrapartum, postpartum, and neonatal care. While the WHO defines BPCR more expansively with as many as nine elements [17], BPCR typically involves learning about danger signs that indicate complications, choosing a health facility for care and delivery, saving money, arranging transport, and choosing a birth companion [17]. BPCR is known to be a powerful intervention to promote the use of skilled care at birth and timely use of facility-based care for obstetric and newborn complications [16, 17].

Tokhi et al. [15] also found that men can provide "substantial practical, financial and emotional support to women and children to overcome demand-side barriers to accessing health services." Men's support can normalize care-seeking, improve healthy behavior; increase couples' communication, and promote equitable decision-making [15]. There is substantial literature showing that couples' communication about family planning (FP) is positively associated with not only modern contraceptive use [18] but also a range of other health behaviors such as ANC attendance, institutional deliveries, and getting an HIV test during ANC [19] Interventional studies in South Africa and India found that facility-based education for men and women increased 
couples' communication about breastfeeding in both countries, the health of their baby in India, and child immunization in South Africa [16].

The State of the World's Fathers 2015 report [20] found that engaging men early-in ways that women want in ANC, childbirth, and postnatal care- can improve women's use of maternal and newborn health services, as well as fathers' long-term support and involvement in the lives of their children. Research from low- and middle-income countries found that male involvement is significantly associated with improved rates of skilled birth attendance and utilization of postnatal care. In high-income countries, the presence of fathers has been shown to encourage and support mothers to breastfeed. Fathers' support also influences women's decision to immunize their children and to seek care for childhood illnesses [20].

A randomized controlled trial evaluating the impact of a couples-focused, community-based intervention in Rwanda found that "culturally adapted gendertransformative interventions with men and couples can be effective at changing deeply entrenched gender inequalities and a range of health-related behavioral outcomes." Participants in the intervention had significant increases in modern contraceptive use, sharing responsibility for housework and childcare, inclusion of women in household financial decision-making, and a modest impact on increased ANC visits. Participants also had reductions in physical and sexual violence against women, and less physical punishment of children [21].

\section{Logic framework for male involvement}

Based on the empirical evidence outlined above and Tokhi et al.'s conceptual framework [15], we propose the logic framework shown in Fig. 1, which considers the specific outcome of institutional delivery. This model explores the impact of sociodemographic factors and illustrates the hypothesis that couple-focused male involvement interventions in RMNCAH, either at the community or facility level, will lead to increased couples' communication about RMNCAH, increased BPCR, and increased male participation in BPCR. Ultimately, these factors lead to higher rates of institutional delivery.

Our study explores the effects of couples' communication and male participation in BPCR on institutional delivery. It also explores the interaction of household wealth with these factors.

\section{Methods}

\section{Study setting and design}

The study data came from a baseline, quantitative, cross-sectional household survey conducted in November 2016 with male and female respondents for an integrated maternal and child health project. The survey was conducted in nine districts in Nampula Province (Ribaué, Mecuburi, Eráti, Mossuril, Meconta, Angoche, Moma, Monapo and Nacala Porto) and four districts in Sofala Province (Beira, Dondo, Buzi and Nhamatanda).

\section{Tool description and implementation}

The Knowledge, Practices and Coverage (KPC) survey tool was used for the baseline survey [22]. The survey is divided into 10 modules focused on RMNCAH, as well as modules on demographics, assets, and gender issues. The standard KPC survey instrument was translated into Portuguese, Macua, and Sena. During the five-day interviewer training, the tool was pre-tested in a comparable community in each province that was just outside the project area. In each household, the mother of a 0-23month-old child was surveyed, asked about her last

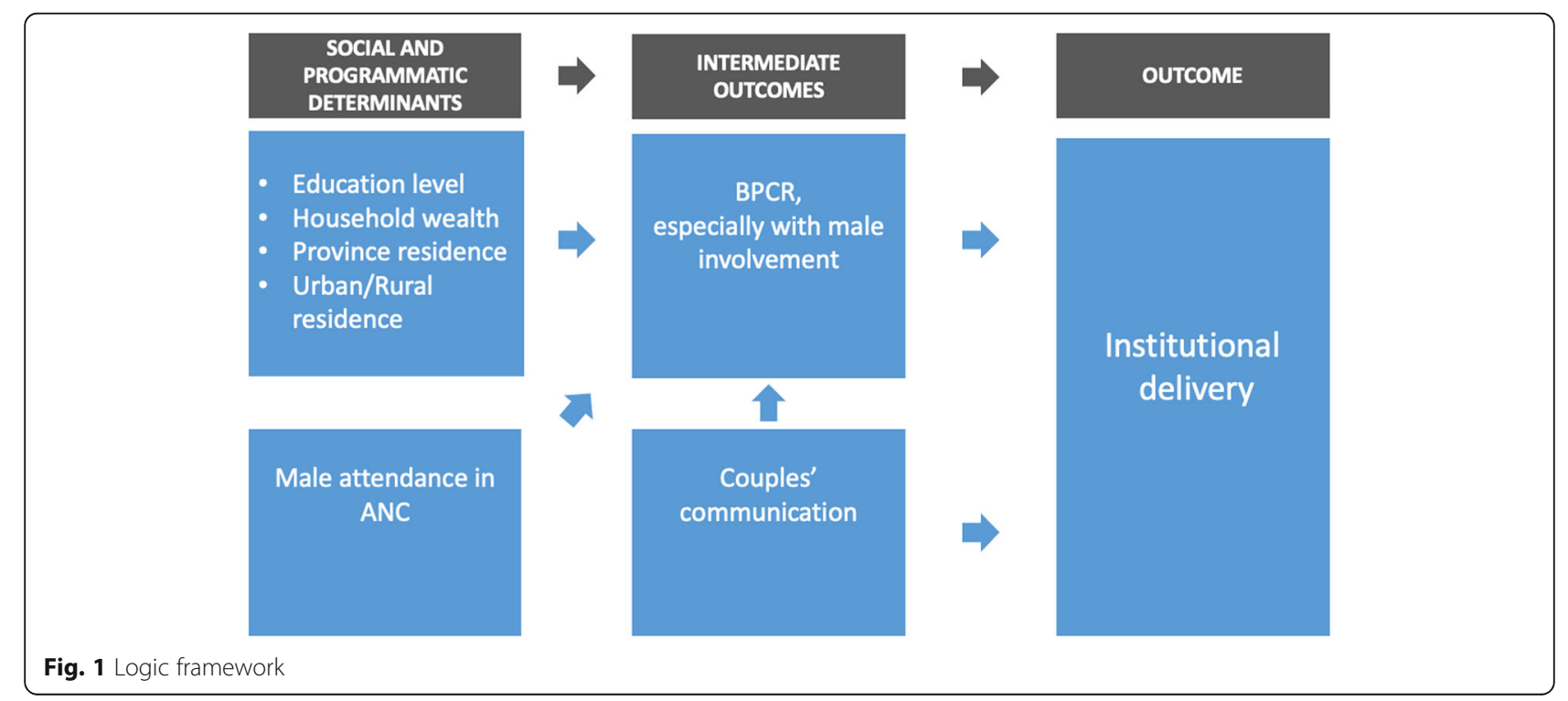


pregnancy, her own health, and the health of her child. We limited respondents to mothers of 0-23 month-olds because the planned project for which this baseline was conducted was only to last 24 months and we wanted to limit respondents in the endline survey to those who received interventions. Female respondents were interviewed by female data collectors on tablet computers, with the survey loaded in CSPro [23]. Data was sent daily from the field to a central server for data review and tabulation.

\section{Sampling methods and study subjects}

The Mozambique National Statistical Institute (INE) conducted data collection using the same two-stage stratified cluster sampling methodology they used for the 2015 IMASIDA [2]. In the first stage, INE used the latest national census, done in 2007, as the sampling frame. The enumeration areas (EAs) were arranged geographically by administrative area, locality, and village (or by neighborhood, in the case of urban EAs). INE chose EAs from this ordered list in a systematic random fashion, with probability proportional to population size. In the second sampling stage, an onsite supervisor who had a map of the EA did a line listing of households, identifying all households with eligible respondents. These were households with women 15 years or older with a child $0-23$ months of age (age $\geq 18$ with her consent; age 15-17 with the additional consent of one of her parents). For the purposes of this study, only heterosexual couples were considered. We did include a men's module in which some of the same questions were asked, and found that men were more likely to report they were involved than their female partner. We decided to use the women's responses, given the likely stronger social desirability bias on the part of men. After a random start, eligible households were systematically sampled until 15 households were visited. Since the geographic area under study is homogenous, there was clumping of wealth scores towards the bottom half of the distribution. Hence the households were divided into three categories consisting of the lowest $60 \%$, less poor $20 \%$, and highest $20 \%$.

\section{Sample size}

The sample size was calculated according to the needs of the integrated maternal and child health project, which used this survey as a baseline, with planned comparisons at endline. We used an estimated design effect of 1.7, which is standard for KPC cluster surveys of this type. There was a desire to show baseline-to-endline differences of at least $10 \%$ for multiple variables of interest, including those starting from a $50 \%$ baseline value, with $80 \%$ power and a 0.05 level of significance. A $10 \%$ nonresponse rate was assumed. Using the standard formula for a $\mathrm{Z}$ statistic for comparison of proportions, this gave a sample of 720 women in the project area in each province and a total sample of 1440 in both provinces, since the sampling was designed to give representative samples in the project area in each province. Fifteen households were selected in 48 clusters in each province (i.e., 96 total clusters).

A post hoc power calculation was performed using a 0.05 level of significance and $80 \%$ power, with various levels of intraclass correlation coefficients (ICC) and reference values for variables of interest in the data set. For the outcome of institutional delivery, which had a baseline indicator value of $84 \%$ and ICC of 0.17 , the minimum detectable difference between two groups would have been $11 \%$.

\section{Analysis}

A wealth index was calculated using the list of household assets according to the methodology adopted by the Demographic and Health Survey (DHS). Using principal components analysis, scores were generated for rural and urban households separately and combined into a single score. Due to the distribution of the scores, the households were divided into three categories consisting of the lowest $60 \%$, less poor $20 \%$, and highest $20 \%$ [24].

The independent variables examined were age (15-24, 25-39, 40-49); education level (no schooling, primary, or secondary and higher); province of residence (Nampula or Sofala); place of residence (urban or rural); wealth categories (lowest $60 \%$, less poor $20 \%$, highest $20 \%)$; and male participation in ANC. Because the study took place in only two provinces with relatively homogenous populations within each province, we did not examine religion or ethnicity.

The woman's report of discussing an FP method with partner was used as a proxy for the status of the couples' communication practices about reproductive health. This was defined as a woman reporting that she discussed the use of an FP method with her partner in the last 12 months. Institutional delivery was defined as a childbirth occurring at a health facility. We chose institutional delivery rather than the presence of a skilled birth attendant because the overwhelming majority of deliveries in Mozambican health facilities are overseen by skilled birth attendants [1], and women often have difficulty accurately reporting distinct cadres of healthcare professionals as "skilled" or "unskilled" compared to the physical location where they delivered [25]. Women were asked separately about each of four elements of BPCR that are germane to male participation and couples' communication: saving money, arranging transport, choosing a birth companion, and choosing a delivery site [26]. Women were also asked separately about their 
partners' participation in each of the four elements of BPCR. Hybrid variables were created for each element of BPCR, assigning a value of zero to women who did not report conducting that BPCR element, "1" to women who carried out the BPCR element without their partners' participation, and "2" to women who did so with the help of their male partners. The results for BPCR are shown as the sum of the number of elements carried out, as well as participation in each of the elements separately, either with or without male partner involvement.

Data were analyzed in STATA version 14.2 [27]. Frequencies and percentages are used to present descriptive statistics. Multivariable logistic regressions were done to test the association between the variables shown in Fig. 2. Bivariate analysis was performed between the variables used as outcomes in the multivariable models and the independent variables described above. The results are not presented in the manuscript but were used in the selection of control variables in the multivariable model. The effective sample size was smaller than the total number of surveys for some variables included in the models because of responses of "Don't Know," which were ignored. The clustering due to the survey design at the level of the enumeration area was accounted for by the use of Huber-White Sandwich estimators. Confidence intervals (CIs) at the $95 \%$ level are presented after adjustment for the independent variables listed above.

\section{Ethical considerations}

This study received ethical approval from the National Bioethics Committee of Mozambique and the Johns Hopkins Bloomberg School of Public Health Institutional Review Board (IRB).

\section{Results}

\section{Description of sample}

A total of 1422 women were interviewed out of a total sample of 1440, representing a $99 \%$ response rate. Even though these data are from a baseline survey for a project in only two of Mozambique's 11 provinces, they draw from a sample that is fairly typical as a crosssection of the overall population of Mozambique. Table 1 describes characteristics of the sample according to four demographic variables: province of residence (a proxy for cultural differences between Sofala in the south, mainly Christian and animist, and Nampula in the north, heavily Muslim and matrilineal), maternal age, educational attainment, and urban/rural residence. About 34\% of the women in the sample had not completed any schooling, compared to $26 \%$ of women in the country as a whole [2]. Seventy-six percent of the sample lived in rural areas, which is similar to the $68 \%$ of the national population living in rural areas in 2016 [28].

\section{Couples' communication and utilization of RMNCAH services}

Table 2 describes couples' communication about FP, women's utilization of ANC and delivery services, and men's attendance at ANC visits. Over $90 \%$ of women attended at least one ANC visit, while $57 \%$ of women attended four or more ANC visits. This is similar to ANC coverage rates for Mozambique as a whole, with 93\% women reporting at least one ANC visit and 54.6\% reporting four or more ANC visits nationally [2]. We found that $84 \%$ of women delivered in a health facility, which is higher than the overall national rate of $70 \%$ in 2015 [2]. Almost 50\% of the women who had attended ANC reported that their partner attended at least one ANC visit with them, which is very similar to the nation as a whole, where the figure from National Health Information System Data was 48\% in 2017 [29]. In the table below, only the positive responses are included for brevity.

The determinants of BPCR actions with and without male partner involvement

Table 3 provides descriptive information about the number and percentage of women who conducted BPCR,

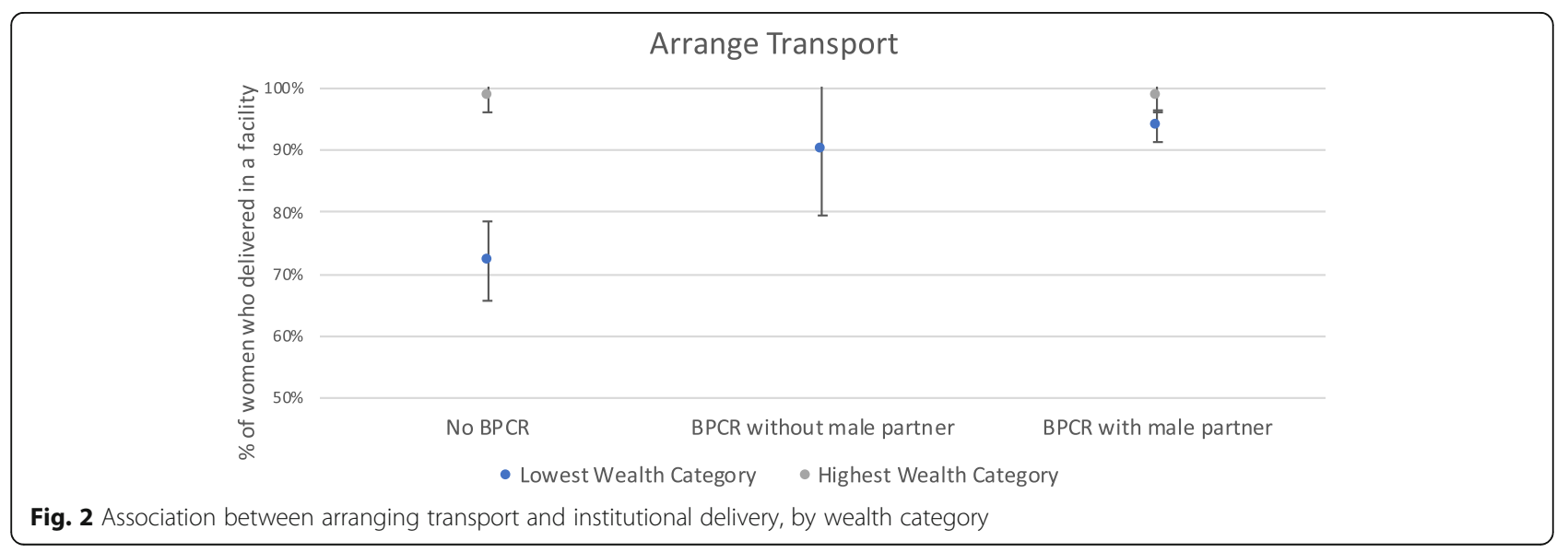


Table 1 Sample characteristics

\begin{tabular}{|c|c|c|}
\hline & \multicolumn{2}{|c|}{ Total $(N=1422)$} \\
\hline & $n$ & $\%$ \\
\hline \multicolumn{3}{|l|}{ Province } \\
\hline Nampula & 720 & $50.6 \%$ \\
\hline Sofala & 702 & $49.4 \%$ \\
\hline \multicolumn{3}{|l|}{ Age } \\
\hline $15-24$ & 746 & $52.5 \%$ \\
\hline $25-39$ & 606 & $42.6 \%$ \\
\hline $40-49$ & 27 & $1.9 \%$ \\
\hline Don't know/No response & 43 & $3.0 \%$ \\
\hline \multicolumn{3}{|l|}{ Education } \\
\hline No school & 478 & $33.6 \%$ \\
\hline Primary school & 656 & $46.1 \%$ \\
\hline Secondary school or superior & 288 & $20.3 \%$ \\
\hline \multicolumn{3}{|l|}{ Residence } \\
\hline Rural & 1077 & $75.7 \%$ \\
\hline Urban & 345 & $24.3 \%$ \\
\hline
\end{tabular}

either with or without their male partner. Of the four elements of birth preparedness planning, saving money was the most common, with close to $70 \%$ of the women reporting that their partner was involved in saving money with them. Fewer than $60 \%$ of women reported that their male partners were involved during their last pregnancy in any of the other three BPCR actions examined: arranging transport, deciding on a birth companion, or choosing the delivery site.

\section{Factors associated with BPCR}

Table 4 explores the factors that influence whether or not BPCR was conducted by women, either alone or with their partner. The $\mathrm{N}$ in Table 4 is smaller than the

Table 2 Reported couples' communication and service utilization

\begin{tabular}{|c|c|c|}
\hline & \multicolumn{2}{|c|}{ Total $(N=1422)$} \\
\hline & $n$ & $\%$ \\
\hline \multicolumn{3}{|c|}{ Couples' communication on FP in past 12 months } \\
\hline Yes & 501 & $35.2 \%$ \\
\hline \multicolumn{3}{|c|}{ ANC visits during most recent delivery } \\
\hline At least one visit & 1333 & $93.7 \%$ \\
\hline Four or more visits & 807 & $56.8 \%$ \\
\hline \multicolumn{3}{|l|}{ Place of delivery } \\
\hline Facility & 1192 & $83.8 \%$ \\
\hline \multicolumn{3}{|c|}{ Male participation in ANC visit ${ }^{a}$} \\
\hline Yes & 662 & $49.6 \%$ \\
\hline
\end{tabular}

${ }^{a} N=1333$ for "male participation in $A N C^{\prime \prime}$
Table 3 Birth Preparedness and Complication Readiness

\begin{tabular}{|c|c|c|}
\hline & \multicolumn{2}{|c|}{ Total $(N=1422)$} \\
\hline & $n$ & $\%$ \\
\hline \multicolumn{3}{|l|}{$\mathrm{BPCR}$} \\
\hline No action & 253 & $17.8 \%$ \\
\hline Saved money ${ }^{a}$ & 964 & $68.2 \%$ \\
\hline Arranged transport & 696 & $48.9 \%$ \\
\hline Chose companion & 776 & $54.6 \%$ \\
\hline Chose delivery site & 830 & $58.4 \%$ \\
\hline All four actions & 470 & $33.1 \%$ \\
\hline All four actions with partner & 409 & $28.8 \%$ \\
\hline \multicolumn{3}{|l|}{ BPCR element A: Saved money ${ }^{a}$} \\
\hline Did not save money & 450 & $31.6 \%$ \\
\hline Saved money without partner & 124 & $8.7 \%$ \\
\hline Saved money with partner & 840 & $59.1 \%$ \\
\hline \multicolumn{3}{|l|}{ BPCR element B: Arranged transport } \\
\hline Did not arrange transport & 726 & $51.1 \%$ \\
\hline Arranged without partner & 62 & $4.4 \%$ \\
\hline Arranged with partner & 634 & $44.6 \%$ \\
\hline \multicolumn{3}{|l|}{ BPCR element C: Chose birth companion } \\
\hline Did not choose companion & 646 & $45.4 \%$ \\
\hline Chose companion without partner & 150 & $10.5 \%$ \\
\hline Chose companion with partner & 626 & $44.0 \%$ \\
\hline \multicolumn{3}{|l|}{ BPCR element D: Chose delivery site } \\
\hline Did not choose delivery site & 592 & $41.6 \%$ \\
\hline Chose delivery site without partner & 165 & $11.6 \%$ \\
\hline Chose delivery site with partner & 665 & $46.8 \%$ \\
\hline
\end{tabular}

overall $\mathrm{N}$ of the survey because respondents who had missing values for any of the six variables included in the regression were excluded. Education, province, residence and wealth status, and couples' communication on FP significantly predicted whether or not BPCR was conducted. Living in Nampula, higher wealth status, male attendance in ANC, and joint communication on FP significantly increased the odds of male participation in BPCR. In fact, the odds of conducting BPCR were $34 \%$ higher (aOR 1.34, 95\% CI 1.05-1.71, $p=0.02$ ) amongst women who communicated with their partner about FP, and the odds were twice as great that they would conduct BPCR with their male partner if they communicated with their male partner about FP (aOR $2.09,95 \%$ CI 1.64-2.67, $p<0.01$ ). Similarly, the odds of conducting $\mathrm{BPCR}$ were $31 \%$ higher $(\mathrm{aOR} 1.31,95 \% \mathrm{CI}$ $0.95-1.82, p=0.1$ ) amongst women whose partner attended ANC, and the odds were $54 \%$ greater that they would conduct BPCR with their male partner (aOR 1.54, 95\% CI 1.15-2.07, $\mathrm{p}<0.01$ ). Educational status was also associated with increased odds, but not in a simple 
Table 4 Factors associated with $B P C R^{a}$ and male participation in $B P C R^{a}$

\begin{tabular}{|c|c|c|c|c|c|c|c|c|}
\hline & \multicolumn{4}{|c|}{$\mathrm{BPCR}(n=1320)$} & \multicolumn{4}{|c|}{ Male participation in BPCR $(n=1320)$} \\
\hline & \multirow{2}{*}{$\begin{array}{l}\text { Adjusted } \\
\text { Odds } \\
\text { Ratio }\end{array}$} & \multicolumn{2}{|c|}{$95 \% \mathrm{Cl}$} & \multirow[t]{2}{*}{$p$-value } & \multirow{2}{*}{$\begin{array}{l}\text { Adjusted } \\
\text { Odds Ratio }\end{array}$} & \multicolumn{2}{|c|}{$95 \% \mathrm{Cl}$} & \multirow[t]{2}{*}{$p$-value } \\
\hline & & $\min$ & $\max$ & & & $\min$ & $\max$ & \\
\hline \multicolumn{9}{|l|}{ Education } \\
\hline No school & 1 & 1 & 1 & . & 1 & 1 & 1 & . \\
\hline Primary school & 1.54 & 1.17 & 2.01 & $<0.01^{*}$ & 1.36 & 1.01 & 1.84 & $0.05^{*}$ \\
\hline Secondary school or superior & 1.37 & 0.88 & 2.13 & 0.16 & 1.27 & 0.74 & 2.18 & 0.39 \\
\hline \multicolumn{9}{|l|}{ Province } \\
\hline Sofala & 1 & 1 & 1 & & 1 & 1 & 1 & \\
\hline Nampula & 3.13 & 1.96 & 4.76 & $<0.01^{*}$ & 1.79 & 1.15 & 2.78 & $0.01 *$ \\
\hline \multicolumn{9}{|l|}{ Residence } \\
\hline Rural & 1 & 1 & 1 & & 1 & 1 & 1 & . \\
\hline Urban & 2.02 & 1.24 & 3.29 & $<0.01^{*}$ & 1.19 & 0.72 & 1.98 & 0.5 \\
\hline \multicolumn{9}{|l|}{ Wealth } \\
\hline Lowest & 1 & 1 & 1 & . & 1 & 1 & 1 & . \\
\hline Less poor & 1.11 & 0.81 & 1.48 & 0.54 & 1.09 & 0.80 & 1.47 & 0.59 \\
\hline Richest & 2.39 & 1.48 & 3.84 & $<0.01^{*}$ & 1.85 & 1.20 & 2.86 & $0.01^{*}$ \\
\hline \multicolumn{9}{|l|}{ Male attendance in ANC } \\
\hline No & 1 & 1 & 1 & . & 1 & 1 & 1 & \\
\hline Yes & 1.31 & 0.95 & 1.82 & 0.1 & 1.54 & 1.15 & 2.07 & $<0.01 *$ \\
\hline \multicolumn{9}{|l|}{ Couples' communication on FP } \\
\hline No & 1 & 1 & 1 & & 1 & 1 & 1 & . \\
\hline Yes & 1.34 & 1.05 & 1.71 & $0.02 *$ & 2.09 & 1.64 & 2.67 & $<0.01^{*}$ \\
\hline
\end{tabular}

* $P$-value significant at 0.05 level

${ }^{a}$ The BPCR indicator was analyzed as an ordinal variable that can take values of $0,1,2,3,4$ elements conducted

manner. Those with primary school education reported the highest levels of BPCR and male participation in BPCR, compared to both those with no schooling and secondary or higher education.

The full model-the effect of male ANC attendance, couples' communication, and BPCR on institutional delivery, controlling for demographic characteristics Table 5 describes factors associated with institutional delivery. As expected, we found that higher educational attainment and wealth status were strong predictors for institutional delivery. In addition, the odds of delivering in a health facility were $46 \%$ higher (aOR 1.46, 95\% CI 1.02-2.10, $p=0.04$ ) among women who did not do BPCR but reported communicating with their partners about FP than women who did not communicate with their partners about FP. Similarly, odds of delivering in a health facility were $33 \%$ greater amongst women who reported communicating about FP with their partner and did BPCR, although the reduced aOR was not found to be significant (aOR 1.33, 95\% CI 0.94-1.89, $p=0.11$ ).

After controlling for education, province, residence, wealth, male attendance in ANC, and couples' communication, there is a significant correlation between the BPCR element of a woman arranging transport on her own and giving birth in a facility (aOR 3.88, 95\% CI 1.03-14.62, $p=0.05$ ), but when done with her partner, this association is even stronger (aOR 4.31, 95\% CI 2.64-7.02, $p<0.01$ ). Furthermore, while a woman choosing a delivery site on her own had an association with institutional delivery which did not reach statistical significance (aOR 1.52, 95\% CI 0.81-2.83, $p=0.19$ ), the odds of delivering in a facility were nearly twice as great amongst women whose partners helped to choose a delivery site (aOR 1.98, 95\% CI 1.16-3.36, $p=0.01$ ).

Male involvement in BPCR is associated with a narrowed gap in institutional delivery rates between wealth categories

Figures 2 and 3 show the associations between elements of BPCR that were significant (arranging transport and choosing a delivery site) and institutional delivery rates by the highest and lowest wealth categories. Note that all women in the highest wealth category arranged transport or chose a place of delivery with their male partner. Among women who did not arrange transport (no 
Table 5 Factors associated with institutional delivery

\begin{tabular}{|c|c|c|c|c|c|c|c|c|}
\hline & \multicolumn{4}{|c|}{ Institutional delivery without BPCR $(n=1320)$} & \multicolumn{4}{|c|}{ Institutional delivery with BPCR $(n=1316)$} \\
\hline & \multirow{2}{*}{$\begin{array}{l}\text { Adjusted }^{a} \\
\text { Odds Ratio }\end{array}$} & \multicolumn{2}{|c|}{$95 \% \mathrm{Cl}$} & \multirow[t]{2}{*}{$p$-value } & \multirow{2}{*}{$\begin{array}{l}\text { Adjusted }^{\mathrm{a}} \\
\text { Odds Ratio }\end{array}$} & \multicolumn{2}{|c|}{$95 \% \mathrm{Cl}$} & \multirow[t]{2}{*}{$p$-value } \\
\hline & & $\min$ & $\max$ & & & $\min$ & $\max$ & \\
\hline \multicolumn{9}{|l|}{ Male attendance in ANC } \\
\hline No & 1 & 1 & 1 & . & 1 & 1 & 1 & . \\
\hline Yes & 1.22 & 0.81 & 1.83 & 0.35 & 0.95 & 0.63 & 1.43 & 0.81 \\
\hline \multicolumn{9}{|c|}{ Couples' communication on FP } \\
\hline No & 1 & 1 & 1 & . & 1 & 1 & 1 & \\
\hline Yes & 1.46 & 1.02 & 2.10 & $0.04 *$ & 1.33 & 0.94 & 1.89 & 0.11 \\
\hline \multicolumn{9}{|c|}{ BPCR element A: Save money } \\
\hline No BPCR & & . & . & & 1 & 1 & 1 & \\
\hline BPCR without partner & & . & . & . & 0.71 & 0.38 & 1.30 & 0.27 \\
\hline BPCR with partner & & . & . & & 1.12 & 0.73 & 1.73 & 0.60 \\
\hline \multicolumn{9}{|c|}{ BPCR element B: Arrange transport } \\
\hline No BPCR & & . & . & & 1 & 1 & 1 & \\
\hline BPCR without partner & . & . & . & . & 3.88 & 1.03 & 14.62 & $0.05^{*}$ \\
\hline BPCR with partner & & . & . & 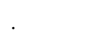 & 4.31 & 2.64 & 7.02 & $<0.01 *$ \\
\hline \multicolumn{9}{|c|}{ BPCR element C: Choose birth companion } \\
\hline No BPCR & . & . & . & . & 1 & 1 & 1 & . \\
\hline BPCR without partner & & . & . & & 0.70 & 0.39 & 1.25 & 0.22 \\
\hline BPCR with partner & & . & . & & 0.76 & 0.51 & 1.15 & 0.20 \\
\hline \multicolumn{9}{|c|}{ BPCR element D: Choose delivery site } \\
\hline No BPCR & & . & . & & 1 & 1 & 1 & \\
\hline BPCR without partner & & & . & & 1.52 & 0.81 & 2.83 & 0.19 \\
\hline BPCR with partner & & . & . & & 1.98 & 1.16 & 3.36 & $0.01 *$ \\
\hline
\end{tabular}

* P-value significant at 0.05 level. ${ }^{a}$ Adjusted for education, province, residence, wealth

BPCR), $99 \%$ of those in the highest wealth category had an institutional delivery, compared to only $72 \%$ of women in the lowest wealth category. Among those who arranged transport with their male partners (BPCR with partner), the difference narrowed to $99 \%$ in the highest wealth category and $94 \%$ in the lowest delivering in a facility.
A similar pattern is seen among women who chose the delivery location. Among women who did not choose a delivery location (No BPCR), 98\% of women in the highest wealth category had an institutional delivery, compared to only $74 \%$ of women in the lowest wealth category. Among women who did choose a delivery

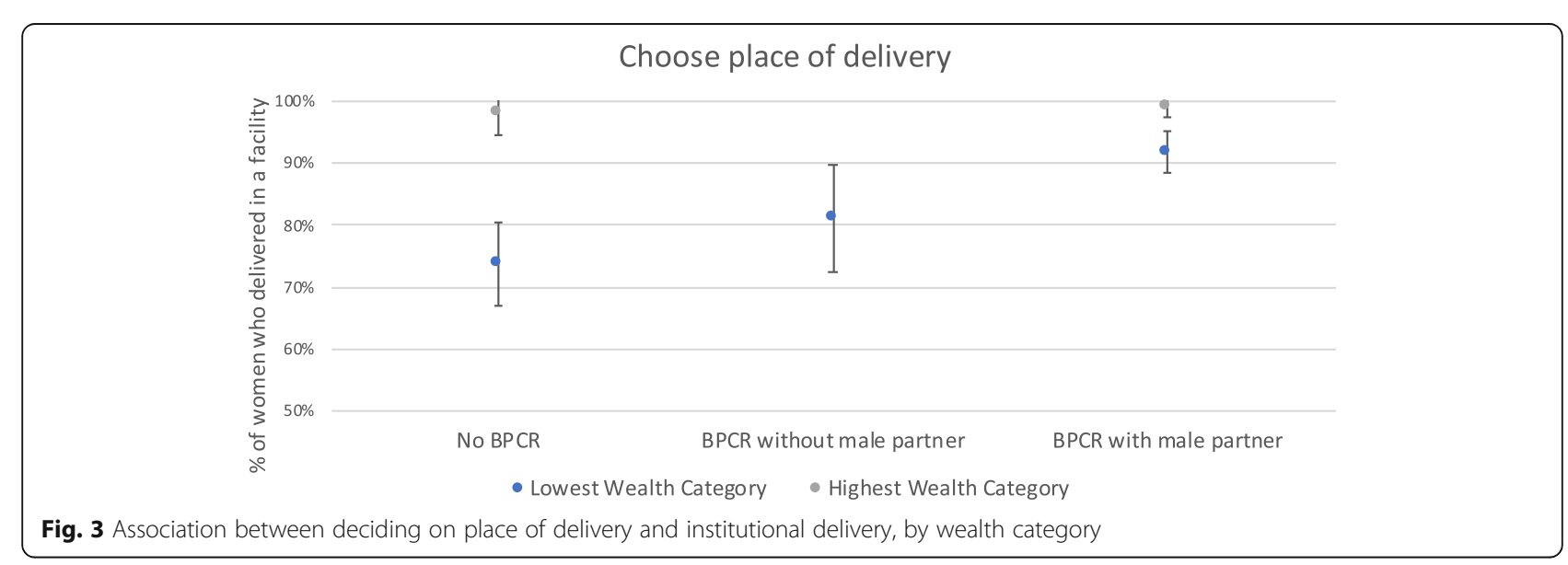


location with their partners (BPCR with partner), $98 \%$ of women in the highest and 92\% of women in the lowest wealth category had an institutional delivery.

\section{Discussion}

Our findings contribute to the increasing global evidence-base that men play an important role in facilitating positive maternal and newborn health behaviors, leading to better outcomes. Increased communication and joint decision-making with partners can lead to increased institutional delivery. The recent systematic review on the effectiveness of interventions to increase involvement of men to improve maternal and newborn health by Tokhi et al. [15] included several interventional studies with positive results on institutional delivery. The authors also found positive effects on couples' communication around a number of health practices, including FP in India [30], breastfeeding in India, South Africa, and Turkey [30-32], and child immunization South Africa [31]. However, the interventional studies that specifically looked at the effect of male involvement on BPCR showed varying results.

Our study found that women whose partners helped them arrange transport or choose a place of delivery were even more likely to have an institutional delivery than the women who carried out these tasks alone. It was already well-established that BPCR is causatively associated with institutional delivery [17]. What is striking in this study is that the odds ratio increased for both arranging transport and choosing a place of delivery when partners were involved in the decision, compared to when women made the decision on their own.

Furthermore, our findings indicate that couples communicated about FP was associated with increased BPCR and rates of institutional delivery. This suggests that the effect of couples' communication on institutional delivery is only partially mediated through the BPCR elements measured. In other words, couples' communication is about more than FP and BPCR and is positively and independently associated with the outcome of institutional delivery. A recent trial in Rwanda found that promoting gender transformative dialogue and couple communication can improve a range of health behaviors [1].

One finding appears to be inconsistent, that is, arranging transport was found to be associated with institutional delivery, but saving money was not. We assume that the money saved was most often used for transport, since there is no cost associated with pregnancy or delivery in a public facility in Mozambique. This warrants further research.

Male participation in ANC had a significant association with male participation in BPCR, and this may be because BPCR is encouraged by providers during ANC visits. Although we cannot ascertain causality due to the cross-sectional nature of this study, the results suggest that male participation in ANC led to their increased knowledge about the importance of BPCR for a healthy and safe delivery. Other studies have found that interventions to increase men's education about maternal and newborn health have led to increased BPCR [3335]; however, we do not know to what extent men's knowledge of maternal and newborn health increased as a result of their participation in ANC.

Our findings are consistent with the logic framework presented here, based on the theory of change proposed by Tokhi et al. [15]. Our framework posits that improved couples' communication is a step towards improving male support to women in accessing RMNCAH services. It is worth noting that we found that not all the effects of couples' communication could be explained through BPCR. There was some residual, unexplained association between couples' communication and institutional delivery. Possible explanations are that the elements of BPCR measured in the survey do not fully encompass the critical aspects of BPCR (e.g., finding someone to care of children); that communication operates through another mechanism, such as immediate joint problem-solving as opposed to planning beforehand for the birth; or that communication is a proxy for an even larger set of behaviors and aspects of the relationship. These possibilities need to be explored through further research, particularly qualitative studies.

Although we do not know if the couples' communication in this study took place before or after birth, there is increasing evidence that men's knowledge [35] and couples' communication about FP are positively associated with modern contraceptive use [18] and a range of other health behaviors, such as attendance to ANC, institutional deliveries, and getting an HIV test during ANC [19, 36-38]. Community-based interventions, particularly with young married couples, have also demonstrated increased contraceptive use, use of ANC, and birth preparedness. A systematic review of such interventions concluded that, "community based interventions targeting young married couples, their immediate family, community members and health service providers contribute positively to improving access and utilization of reproductive health services in resourceconstrained settings of low and middle-income countries" [39]. Moreover, it is interesting to note that the odds ratio for couples' communication did not change when adjusted for wealth, education, or place of residence. This finding is consistent with the idea that couples' communication and joint decision-making can be equally effective across demographic categories. A 2018 report by the United States Agency for International Development on involving men and boys to improve FP 
outcomes looked at DHS data from 40 countries on men's attitudes about reproductive health. The report concluded that men who have more equitable attitudes towards FP (e.g. such as believing it is both the man's and the woman's responsibility) and about family roles (e.g., men who share decision-making with women) are more likely to report using an FP method. The report also found that open communication about FP between couples helps facilitate men's support for-and women's use of-contraception [40].

Another important finding from our study was that male participation seems to narrow the gap between the lowest and highest wealth categories in terms of institutional delivery. Nearly all women in the highest category had an institutional delivery. In comparison, $72 \%$ of women in the lowest category who did not arrange transport had an institutional delivery. But $90 \%$ of poor women who arranged transport alone delivered in a facility as did $94 \%$ of poor women who arranged transport with their male partner. A similar pattern was seen among poor women with respect to choosing a birth location: $74 \%$ who did not choose a location had a facility delivery, as did $81 \%$ who chose a location without their partner and $92 \%$ of those who chose with their partner. These findings confirm a growing body of research that demonstrates the importance of addressing the intersectionality of gender inequality with other constraints and vulnerabilities, such as poverty and other social stigmas, when accessing maternal newborn care $[41,42]$. There may be a number of reasons why men's participation in BRCP narrows the gap of institutional delivery between the rich and the poor. Men's participation may, for example, make up for the fact that women in the poorer group may not be able to afford transport on their own but can do so with the help of their male partners. These should be explored through further research, including qualitative means.

Because this was a cross-sectional survey, it is not possible to draw conclusions regarding the way in which decisions were made about BPCR or, ultimately, institutional deliveries. It is possible that male participation, without intentional efforts to promote gender equity in couples' communication and decision-making, could lead to the erosion of women's agency in decisionmaking. For example, the qualitative study by Audet, et al. on the barriers to male involvement in ANC in rural Mozambique found that men's desire or perceived right to control their pregnant partners may be the root of some men's interest to be involved in ANC [7]. The WHO recognizes that male involvement is only helpful when it is "implemented in a way that respects, promotes and facilitates women's choices and their autonomy in decision-making and supports women in taking care of themselves and their newborns" [16]. In some cases, male involvement could be an aspect of control, i.e. a lack of gender equity, and in others, an expression of egalitarian concern and care. Similarly, a woman's ability to plan and execute BPCR on her own could be seen as an expression of her own autonomy or as a strategy used by women in otherwise highly inequitable situations. This is an area where additional qualitative research would be helpful. Others have found that in African countries, gender equality, as measured by women's level of decision-making regarding health care, the purchase of major household goods, the purchase of daily goods, and visits to family/friends, as well as attitudes opposing gender-based violence, is associated with institutional deliveries, child immunization, and careseeking for child health [43]. On the other hand, according to the DHS, men in Africa are still key decision makers in health overall, and, therefore, their support for institutional delivery would logically increase its likelihood However, there may be other underlying factors causing the association, which deserve further exploration.

\section{Strengths and limitations}

Despite being a small study in two provinces, this study yielded important information about the association between couples' communication, male engagement, and improved health behaviors. This poses important implications for policy makers and program managers when considering approaches and populations to include in reproductive and maternal health programming.

The greatest limitation is that the study was crosssectional and not interventional; therefore, the extent to which correlations are causative is only suggestive. For instance, we did not ask if the current partner was the same partner who impregnated the woman, nor if the communication on FP preceded the birth or came afterwards. We also did not measure the distance from respondent's communities to the nearest health facility, a factor that is known to have an effect on institutional delivery rates. The study relied on self-reporting, and could have been affected by recall bias and social desirability bias, for example, when women were asked about their male partner's behavior.

An additional limitation is that the data for this analysis came from a household survey that served as the baseline for a project intervening in multiple RMNCAH areas (maternal health, nutrition, immunization, etc.), but not specifically designed for the purposes of evaluating male engagement and couples' communication. This means that we were not able to ask additional in-depth questions because the survey already took almost $2 \mathrm{~h}$ to administer. The sample size calculation for the survey did not take into account the likelihood of small cell sizes for some sub-analyses we performed, such as the 
interaction of wealth and BPCR. Given the large number of technical areas that the baseline study needed to cover, it was not feasible to delve into any issue in great detail in the survey instrument. In terms of measuring couples' communication, the one question that was included was specifically about communication about FP, but there were no questions about communication on other RMNCAH topics. We have, however, presented some published evidence that couples' communication on FP has previously been associated with other RMNCAH outcomes when used as a proxy for more general communication on RMNCAH. We were not able to explore issues of either the quality of male engagement, i.e., the extent to which it might be coercive, or women's empowerment; e.g., did male engagement decrease female agency or interact with it in significant ways? We plan to explore these issues in a mixed methods endline evaluation of the project's gender interventions for couples' communication and male engagement through a repeat of the quantitative KPC survey and a qualitative component. Finally, it was beyond the scope of this paper to explore the nature of cultural differences between provinces and their exact relation to male participation for birth preparation and in the birthing process itself. However, we tried to take account of these differences by including "province" as a dummy variable in all regression models that we ran.

\section{Conclusion}

Couples' communication matters. Strategies to promote couples' communication in RMNCAH interventions should be encouraged by $\mathrm{MOH}$ and policies and guidelines for both facility-based health provider practices and community-based health promotion efforts. Couples' communication's effect on institutional delivery appears to only be partially mediated through BPCR. The ways in which couples' communication contributes to BPCR and to institutional delivery, whether it represents communication beyond BPCR, or whether other factors in the relationship are at play, still need further exploration through qualitative means. More evidence is also needed on the effectiveness of couple communication across a variety of settings. There are two main components of BPCR we found to be associated with higher institutional delivery rates-arranging transport and choosing location of delivery-and male engagement strengthens their association. BPCR, especially BPCR with male involvement, seems to close the gap between the wealth categories in terms of institutional delivery rates. This suggests that male engagement and couples' communication interventions could be an important intervention for improving RMNCAH among women in lower wealth categories. Further qualitative studies need to be done to explore these findings in depth.

\section{Abbreviations}

ANC: Antenatal care; aOR: Adjusted odds ratio; BPCR: Birth preparedness and complication readiness; Cl: Confidence interval; DHS: Demographic and Health Survey; EA: Enumeration areas; FP: Family planning; HIV: Human immunodeficiency virus; ICC: Intraclass correlation coefficient; IMASIDA: National Survey on Immunization, Malaria, and HIV/AIDS; INE: Mozambique National Statistical Institute; IRB: Institutional Review Board; KPC: Knowledge, Practices, and Coverage Survey Tool; MNH: Maternal and newborn health; RMNCAH: Reproductive, maternal, newborn, child and adolescent health; USAID: United States Agency for International Development; WHO: World Health Organization

\section{Acknowledgements}

The authors are grateful for the support of the Instituto Nacional de Estatistica, which designed the sampling methodology, to Jennifer Winestock-Luna for her contributions to the development of the KPC survey tools, and to the following experts who reviewed manuscript drafts and provided invaluable feedback: Maria da Luz Vaz, Eric Ramirez-Ferrero, Kathryn Boryc Smock, Mercino Ombe, Michel Congolo, Niyati Shah, Elizabeth ArlottiParish, and Lilit Hakobyan.

\section{Authors' contributions}

All authors analyzed and interpreted data, contributed to the writing of the manuscript, edited and approved the final manuscript. GGS, JB, JR, CSL, and MLB designed and adapted the study tools. MLB and CSL helped

conceptualize the analysis. JB led writing of the manuscript, led the literature search, extracted relevant data from articles, led editing the manuscript, and managed manuscript submission. DM led statistical analysis of the study findings. GGS, JR, CSL, MLB, and RMMC contributed to reviewing, data analysis, writing, and editing the manuscript.

\section{Funding}

This study was made possible by the generous support of the United States Agency for International Development (USAID) under the terms of the Cooperative Agreement AID-OAA-A-14-00028. The contents are the responsibility of the Maternal and Child Survival Program and do not necessarily reflect the views of USAID or the United States Government, which did not make the decision to publish. USAID did not have a role in the design of the study; the collection, analysis, or interpretation of data; or in writing the manuscript. USAID did review the manuscript and provided feedback, which the authors considered and voluntarily integrated into the manuscript.

\section{Availability of data and materials}

The data that support these findings are available upon reasonable request to the corresponding author.

\section{Ethics approval and consent to participate}

The study team received ethical approval to conduct the KPC baseline study from the Comité Nacional de Bioetica Para Saúde (Mozambique National Bioethics Committee for Health, Study \#284/CNBS/16) and the Johns Hopkins Bloomberg School of Public Health Institutional Review Board (IRB Study \#7178).

Informed, written consent was obtained from all study participants. Data collectors provided participants with consent forms and read them aloud, which were then signed by all participants and verified by the study team. The consent forms were approved by both the Comité Nacional de Bioetica Para Saúde of Mozambique and the Johns Hopkins Bloomberg School of Public Health Institutional Review Board.

Consent for publication

All authors have approved the final version of this manuscript.

\section{Competing interests}

The authors declare that they have no competing interests.

\section{Author details}

${ }^{1}$ Maternal and Child Survival Program/ Jhpiego, Avenida Armando Tivane n', 1620 Maputo, Mozambique. ${ }^{2}$ Maternal and Child Survival Program/ Jhpiego, 1776 Massachusetts Ave, NW, Suite 300, Washington, DC 20036, USA. ${ }^{3}$ The Johns Hopkins University Bloomberg School of Public Health, 615 N. Wolfe

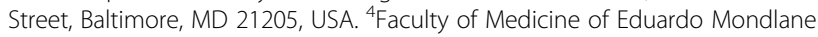


University and National Ministry of Health, Eduardo Mondlane Ave, Maputo, Mozambique.

\section{Received: 8 February 2019 Accepted: 3 May 2020 Published online: 11 June 2020}

\section{References}

1. WHO, UNICEF, UNFPA and United Nations Population Division. Trends in Maternal Mortality: 1990 to 2015. Geneva, Switzerland, 2015. In World Bank Data Catalog. Accessed 1 Nov 2019. http://www.who.int/gho/maternal_ health/countries/moz.pdf.

2. Ministério da Saúde and ICF International. Inquérito de Indicadores de Imunização, Malária e HIV/SIDA em Moçambique 2015 (IMASIDA). Rockville: Ministério da Saúde, Instituto Nacional de Estatiś tica and ICF International; 2015.

3. Pathfinder International Mozambique. Barriers to institutional deliveries and family planning: A qualitative study from Cabo Delgado, Zambezia and Inhambane provinces, Mozambique. Study commissioned by Department for International Development (DFID); 2013.

4. Victor B, Fisher E, Cooil B, Vergara A, Mukolo A, Blevins M. Frustrated freedom: the effects of agency and wealth on wellbeing in rural Mozambique. World Dev. 2013;47:30-41.

5. Ministério da Saúde- Moçambique, Instituto Nacional de EstatísticaMoçambique, and ICF International. Moçambique Inquérito Demográfico e de Saúde (Demographic and Health Survey). Maryland: ICF International; 2011.

6. Bandali S. Norms and practices within marriage which shape gender roles, HIV/AIDS risk and risk reduction strategies in Cabo Delgado, Mozambique. AIDS Care. 2011;23(9):1171-6.

7. Audet CM, Chire YM, Vaz LM, Bechtel R, Carlson-Bremer D, Wester CW Amico KR, Gonzalez-Calvo L. Barriers to male involvement in antenatal Care in Rural Mozambique. Qual Health Res. 2016;26(12):1721-31

8. Cuco RM, Munguambe K, Bisque Osman N, Degomme O, Temmerman M, Sidat M. Male partners' involvement in prevention of mother-to-child HIV transmission in sub-Saharan Africa: a systematic review. SAHARAJ. 2015; 12(1):87-105.

9. Koo K, Makin JD, Forsyth BW. Barriers to male-partner participation in programs to prevent mother-to-child HIV transmission in South Africa. AIDS Educ Prev. 2013;25(1):14-24.

10. Kwambai TK, Dellicour S, Desai M, Ameh CA, Person B, Achieng F, Mason L, Laserson KF, Ter Kuile FO. Perspectives of men on antenatal and delivery care service utilisation in rural western Kenya: a qualitative study. BMC Pregnancy Childbirth. 2013;13:134.

11. Larsson EC, Thorson A, Nsabagasani X, Namusoko S, Popenoe R, Ekstrom AM. Mistrust in marriage--reasons why men do not accept couple HIV testing during antenatal care- a qualitative study in eastern Uganda. BMC Public Health. 2010;10:769.

12. Orne-Gliemann J, Tchendjou PT, Miric M, Gadgil M, Butsashvili M, Eboko F, Perez-Then E, Darak S, Kulkarni S, Kamkamidze G, et al. Couple-oriented prenatal HIV counseling for HIV primary prevention: an acceptability study. BMC Public Health. 2010;10:197.

13. Greene ME, Mehta M, Pulerwitz J, Wulf D, Bankole A, Singh S. Involving men in reproductive health: contributions to development. UN Millennium Project; 2006.

14. Sternberg P, Hubley J. Evaluating men's involvement as a strategy in sexual and reproductive health promotion. Health Promot Int. 2004;19(3):389-96.

15. Tokhi M, Comrie-Thomson L, Davis J, Portela A, Chersich M, Luchters S. Involving men to improve maternal and newborn health: a systematic review of the effectiveness of interventions. PLoS One. 2018;13(1):e0191620.

16. World Health Organization. WHO recommendations on health promotion interventions for maternal and newborn health. Geneva: WHO; 2015.

17. Soubeiga D, Gauvin L, Hatem MA, Johri M. Birth preparedness and complication readiness (BPCR) interventions to reduce maternal and neonatal mortality in developing countries: systematic review and metaanalysis. BMC Pregnancy Childbirth. 2014;14:129.

18. Pratley P. Associations between quantitative measures of women's empowerment and access to care and health status for mothers and their children: a systematic review of evidence from the developing world. Soc Sci Med. 2016;169:119-31.

19. Naugle D. Leveraging spousal communication as a gateway behavior in the context of an integrated health Project in Mali. Nusa Dua, Indonesia:
Presented at International Social and Behavior Change Communication Summit; 2018.

20. Levtov R, van der Gaag N, Greene M, Kaufman M, Barker G. State of the World's fathers: a MenCare advocacy publication. Washington, DC: Promundo, Rutgers University, Save the Children, Sonke Gender Justice, and the MenEngage Alliance; 2015.

21. Doyle K, Levtov RG, Barker G, Bastian GG, Bingenheimer JB, Kazimbaya S, Nzabonimpa A, Pulerwitz J, Sayinzoga F, Sharma V, et al. Gendertransformative Bandebereho couples' intervention to promote male engagement in reproductive and maternal health and violence prevention in Rwanda: findings from a randomized controlled trial. PLoS One. 2018; 13(4):e0192756.

22. Child Survival Support Project, Macro International, CORE Group, MCHIP, Maternal and Child Survival Program: Knowledge, Practices and Coverage Survey Tool. 2018.

23. US Census Bureau and ICF Macro. Census and Survey Processing System (CSPro Software version 7.2). U.S. Census Bureau and ICF Macro. 2019. https://www.census.gov/data/software/cspro.html. Accessed 1 May 2019.

24. Rutstein SO. Steps to constructing the new DHS wealth index. DHS Program. https://dhsprogram.com/programming/wealth\%20index/Steps_ to_constructing_the_new_DHS_Wealth_Index.pdf. Accessed 29 May 2020

25. Radovich E, Benova L, Penn-Kekana L, Wong K, Campbell OMR. 'Who assisted with the delivery of (NAME)?' Issues in estimating skilled birth attendant coverage through population-based surveys and implications for improving global tracking. BMJ Glob Health. 2019;4(2):e001367.

26. Jhpiego. Monitoring birth preparedness and complication readiness tools and indicators for maternal and newborn health. Baltimore: Jhpiego; 2005

27. StataCorp: Stata Statistical Software: Release 14. College Station: Stata Corp; 2015. https://www.stata.com/products/. Accessed 1 May 2019.

28. Trading Economics: Mozambique- Rural Population. 2018. Accessed 1 Nov 2018. https://tradingeconomics.com/mozambique/rural-populationwb-data.html.

29. Ministério da Saúde: National Health Information System. 2018.

30. Varkey LC, Mishra A, Das A, Ottolenghi E, Huntington D, Adamchak S, et al. Involving men in maternity care in India. Frontiers in Reproductive Health Program, Population Council. 2004.

31. Kunene B, Beksinska M, Zondi S, Mthembu N, Mullick S, Ottolenghi E, et al. Involving men in maternity care. Reproductive Health Research Unit (Durban) and Department of Obstetrics and Gynaecology, University of Witswatersrand. 2004.

32. Sahip Y, Turan JM. Education for expectant fathers in workplaces in Turkey. J Biosoc Sci. 2007;39(6):843-60.

33. Fullerton JT, Killian R, Gass PM. Outcomes of a community- and homebased intervention for safe motherhood and newborn care. Health Care Women Int. 2005;26(7):561-76.

34. Sood SCU, Palmer A, Molyneux I. Measuring the effects of the SIAGA behaviour change campaign in Indonesia with population based survey results. Baltimore: Jhpiego; 2004.

35. Ezeanolue EE, Iwelunmor J, Asaolu I, Obiefune MC, Ezeanolue CO, Osuji A, Ogidi AG, Hunt AT, Patel D, Yang W, et al. Impact of male partner's awareness and support for contraceptives on female intent to use contraceptives in Southeast Nigeria. BMC Public Health. 2015;15:879.

36. Bawah AA. Spousal communication and family planning behavior in Navrongo: a longitudinal assessment. Stud Fam Plan. 2002;33(2):185-94.

37. Furuta M, Salway S. Women's position within the household as a determinant of maternal health care use in Nepal. Int Fam Plan Perspect. 2006:32(1):17-27.

38. August F, Pembe AB, Mpembeni R, Axemo P, Darj E. Community health workers can improve male involvement in maternal health: evidence from rural Tanzania. Glob Health Action. 2016;9:30064.

39. Sarkar A, Chandra-Mouli V, Jain K, Behera J, Mishra SK, Mehra S. Community based reproductive health interventions for young married couples in resource-constrained settings: a systematic review. BMC Public Health. 2015; 15:1037.

40. USAID. Essential Considerations for Engaging Men and Boys for Improved Family Planning Outcomes. Washington, DC: USAID; 2018.

41. Dhar D, McDougal L, Hay K, Atmavilas Y, Silverman J, Triplett D, Raj A. Associations between intimate partner violence and reproductive and maternal health outcomes in Bihar, India: a cross-sectional study. Reprod Health. 2018;15(1):109. 
42. Morgan R, Tetui M, Kananura RM, Ekirapa-Kiracho E, George AS. Gender dynamics affecting maternal heatlh and health care access and use in Uganda. Health Policy Plan. 2017;32:v13-21.

43. Singh K, Bloom S, Brodish P. Gender equality as a means to improve maternal and child health in Africa. Health Care Women Int. 2015;36(1):5769.

\section{Publisher's Note}

Springer Nature remains neutral with regard to jurisdictional claims in published maps and institutional affiliations.

Ready to submit your research? Choose BMC and benefit from:

- fast, convenient online submission

- thorough peer review by experienced researchers in your field

- rapid publication on acceptance

- support for research data, including large and complex data types

- gold Open Access which fosters wider collaboration and increased citations

- maximum visibility for your research: over $100 \mathrm{M}$ website views per year

At BMC, research is always in progress.

Learn more biomedcentral.com/submissions 